\title{
Meaning Correlates of Mental Pain in Pediatric Cancer Survivors
}

\author{
Haya $\operatorname{Raz}^{1}$ and Shulamith Kreitler ${ }^{2 *}$ \\ ${ }^{1}$ School of Nursing, Faculty for Life Sciences and Health, Tal Campus, Israel \\ ${ }^{2}$ School of Psychological Science, Tel-Aviv University and Psychooncology Research, Center, Sheba Medical Center, Tel Hashomer, Israel
}

*Corresponding Author: Shulamith Kreitler, School of Psychological Science, Tel-Aviv University and Psychooncology Research, Center, Sheba Medical Center, Tel Hashomer, Israel.

Received: June 28, 2019; Published: July 31, 2019

DOI: 10.31080/ASNE.2019.02.0090

\begin{abstract}
The objective was to examine cognitive correlates of mental pain (MP) experiences in adult survivors of pediatric cancer in terms of meaning assignment tendencies. The hypotheses were that MP in the present and in the past would correspond to a pattern of meaning variables reflecting the subjects approach to MP.

Method: The sample included 61 adult childhood cancer survivors (mean age was 25.03 years (SD = 5.56) ranging from 18 to 41 years), who had been diagnosed and treated, mostly ( $n=27$ ) for lymphoma, $M=12.84$ years ago, at the age of $M=12.2$ years. The tools were: A background information questionnaire; The MP questionnaire (Orbach) and the Test of Meanings (Kreitler).

Results: A two-step factor analysis of the meaning variables yielded eight meaning-based factors shared by MP in the present and in the past. Regression analyses with age, gender and marital status in the first step and the eight meaning-based predictors in the second step provided significant results showing that MP in the past was related to more predictors than MP in the present and focused mainly on shifting away through avoidance and negation from the painful themes this preventing coping with them productively. The results provide guidelines for coping interventions.
\end{abstract}

Keywords: Pediatric Cancer; Meaning System; Mental Pain; Cancer Survivors

Meaning correlates of mental pain in pediatric cancer survivors

The objective was to examine cognitive correlates of mental pain experiences in adult survivors of pediatric cancer. The specific correlates on which the study focuses are meaning assignment tendencies, such as tendencies to focus on functions of objects or emotional manifestations or temporal and locational characteristics that mediate the manner in which an individual perceives and conceptualizes the world around or within him or her. Previous studies were devoted to identifying the sets of meaning assignment tendencies corresponding to constructs such as personality traits or specific emotions [1-5]. Sets of meaning assignment tendencies provide insights into the nature and functioning of the studied construct and enable planning guidelines for improved coping.
The number of patients who survive pediatric cancer is about $80 \%$ and is increasing [6]. This situation has prompted an expanding effort to examine the late effects of pediatric cancer and its treatments so as to devise improved methods for helping the patients and their families. The medical problems of pediatric cancer survivors are common and have been the theme of many studies [7]. The psychological problems of pediatric cancer survivors are likely to be no less frequent in view of the duration, the difficulties, the pain and the anxiety often involved in undergoing the procedures of diagnosis, testing and treatments for pediatric cancer $[8,9]$. Studies show that in comparison to healthy subjects pediatric cancer survivors have a lower QOL [10], poor self-esteem and academic difficulties [11]. lower self-concept [12], more depression, anxiety, pain, and insomnia [13], fatigue, emotional symptoms 
[14], posttraumatic stress [15], difficulties at work and marriage $[16,17]$, and to some extent even suicide ideation [18-21].

\section{Mental pain}

Findings about the mental state of pediatric cancer survivors inspired a study about their mental pain (MP). The results showed that in the survivors MP scores were higher than in regular subjects and were related negatively to quality of life [22].

MP is a negative emotional experience, different from anxiety and depression with which it may share some features [23], reflecting mainly existential dissatisfaction, loss of meaning, and low self-esteem [24] suicidal tendencies [25,26].

The assumption underlying the present study was that MP is a kind of experience shaped at least to some extent by the meanings assigned by the individuals to oneself and one's situation. This assumption was grounded in the frequent references to loss of meaning in general and of meaningfulness of life in particular made in association with MP [8,23,27-29].

\section{Meaning}

In order to assess the meanings characteristic of individuals suffering from MP we focused on assessing characteristic meaning assignment tendencies of these individuals. The rationale was that these tendencies would manifest more characteristic tendencies than meanings of specific constructs, even those that are close to the investigated domain. The meaning assignment tendencies were assessed in terms of the Kreitler Meaning System, which is a comprehensive, empirically-based and broadly tested theoretical framework for conceptualizing and assessing meaning.

According to the Kreitler Meaning System meaning is defined as a referent-centered pattern of meaning values. In this definition, referent is the input, the carrier of meaning, which can be anything, such as a word, an object, or a situation, whereas meaning values are cognitive contents assigned to the referent in order to express or communicate its meaning. For example, when the referent is 'Table', responses such as 'made of wood' or 'stands in a room' are two different meaning values. The referent and the meaning value together form a meaning unit (e.g., Table - made of wood) [3]. Most descriptions of meaning include more than one meaning unit. Meaning is assessed by means of six sets of variables, defined on the basis of analyzing thousands of meaning responses provided by individuals differing in culture, gender and age. These variables characterize the contents, structure and modes of expression of the meaning units. Table 1 presents a full list of meaning variables and Table 2 provides their definitions accompanied by examples.
A body of studies shows that each of the meaning variables represents a domain of contents and the processes involved in its activation. For example, the meaning variable of Function represents the set of contents related to function e.g., it enables X, it serves $\mathrm{Y}$ ) and the cognitive processes involved in thinking about function. Accordingly, each meaning variable is actually a meaning assignment tendency which the individual applies for comprehending external and internal stimuli and situations. Thus, the meaning variable of emotions for example is used by the individual for identifying emotional stimuli and perceiving situations in terms of their emotional connotations.

However, most psychological acts, like planning or recalling or experiencing an emotion are complex events in which more than one meaning variable is involved. Thus, each of these acts was found to correspond to a set of meaning variables, Such profiles of meaning variables were identified, for example, for spatial navigation, art evaluation, curiosity, creativity, cognitive conservation, problem solving, planning, learning of reading, interest, and reading comprehension [4,5,31-33,36-45]. Moreover, patterns of meaning variables have been identified also for personality traits (e.g., extroversion, openness) [18], personality tendencies (e.g., resilience) [33], defense mechanisms (e.g. projection, denial) [32]. constructs like meaningfulness of life [17] or value orientation [14], as well as for emotions, like fear, anger, anxiety, and depression [19,26].

There are two important benefits to identifying the patterns of meaning variables corresponding to a psychological construct. First, the meaning variables in the pattern provide insights into the nature and functioning of the psychological construct, for example, in regard to anxiety they show that it consists in focusing on metaphors and one's sensations and disregarding action and reality. Secondly, the strength of the construct may be changed by changing the salience and strength of the meaning variables constituting the pattern.

Both the insight into the functioning of the construct and the possibility of changing the meaning variables constituting the pattern indicate that the pattern of meaning variables corresponding to the construct may be considered as a strategy of coping with the situation underlying the construct or to which the construct refers [1].

The three main results of the previous studies that contributed directly to the theoretical and methodological foundation of the present study were first, the recurrent finding that psychological constructs correspond to patterns of meaning variables; that meaningfulness of life was one of the constructs for which a pattern of meaning variables was identified; and that various emotions were 


\begin{tabular}{|c|c|c|c|}
\hline \multicolumn{2}{|r|}{ Meaning Dimensions ${ }^{\mathrm{d}}$} & \multicolumn{2}{|r|}{ Forms of Relation } \\
\hline Dim. 1 & Contextual Allocation & FR 1 & Propositional (1a: Positive; 1b: Negative) \\
\hline Dim. 2 & Range of Inclusion (2a: Sub-classes; 2b: Parts) & FR 2 & Partial (2a: Positive; 2b: Negative) \\
\hline Dim. 3 & Function, Purpose and Role & FR 3 & Universal (3a: Positive; 3b: Negative) \\
\hline Dim. 4 & $\begin{array}{l}\text { Actions and Potentialities for Actions ( } 4 \mathrm{a} \text { : by referent; } 4 \mathrm{~b} \text { : } \\
\text { to referent) }\end{array}$ & FR 4 & Conjunctive (4a: Positive; 4b: Negative) \\
\hline Dim. 5 & Manner of Occurrence and Operation & FR 5 & Disjunctive (5a: Positive; 5b: Negative) \\
\hline Dim. 6 & Antecedents and Causes & FR 6 & Normative (6a: Positive; 6b: Negative) \\
\hline Dim. 7 & Consequences and Results & FR 7 & Questioning (7a: Positive; 7b: Negative) \\
\hline Dim. 8 & Domain of Application (8a: as subject; 8b: as object) & FR 8 & Desired, wished (8a: Positive; 8b: Negative) \\
\hline Dim. 9 & Material & \multicolumn{2}{|r|}{ SHIFTS IN Referent ${ }^{\mathrm{b}}$} \\
\hline Dim. 10 & Structure & SR 1 & Identical \\
\hline Dim. 11 & State and Possible change in it & SR 2 & Opposite \\
\hline Dim. 12 & Weight and Mass & SR 3 & Partial \\
\hline Dim. 13 & Size and Dimensionality & SR 4 & Modified by addition \\
\hline Dim. 14 & Quantity and Mass & SR 5 & Previous meaning value \\
\hline Dim. 15 & Locational Qualities & SR 6 & Association \\
\hline Dim. 16 & Temporal Qualities & SR 7 & Unrelated \\
\hline Dim. 17 & Possessions (17a) and Belongingness (17b) & SR 8 & Verbal label \\
\hline Dim. 18 & Development & SR 9 & Grammatical variation \\
\hline Dim. 19 & Sensory Qualities ${ }^{\mathrm{c}}$ (19a: of referent; 19b: by referent) & SR 10 & Previous meaning values combined \\
\hline Dim. 20 & $\begin{array}{l}\text { Feelings and Emotions (20a: evoked by referent; 20b: felt } \\
\text { by referent) }\end{array}$ & SR 11 & Superordinate \\
\hline Dim. 21 & $\begin{array}{l}\text { Judgments and Evaluations (21a: about referent; 21b: by } \\
\text { referent) }\end{array}$ & SR 12 & $\begin{array}{l}\text { Synonym (12a: in original language; } 12 \mathrm{~b} \text { : trans- } \\
\text { lated in another language; } 12 \mathrm{c} \text { : label in another } \\
\text { medium; } 12 \mathrm{~d} \text { a different formulation for the same } \\
\text { referent on the same level) }\end{array}$ \\
\hline Dim. 22 & $\begin{array}{l}\text { Cognitive Qualities (22a: evoked by referent; } 22 \mathrm{~b} \text { : of refer- } \\
\text { ent) }\end{array}$ & SR 13 & Replacement by implicit meaning value \\
\hline \multicolumn{2}{|r|}{ Types of Relation $^{\text {a }}$} & \multicolumn{2}{|r|}{ Forms of Expression } \\
\hline TR 1 & $\begin{array}{l}\text { Attributive (1a: Qualities to substance; 1b: Actions to } \\
\text { agent) }\end{array}$ & FE 1 & $\begin{array}{l}\text { Verbal (1a: Actual enactment; 1b: Verbally } \\
\text { described; 1c: Using available materials) }\end{array}$ \\
\hline TR 2 & $\begin{array}{l}\text { Comparative (2a: Similarity; 2b: Difference; 2c: } \\
\text { Complementariness; 2d: Relationality }\end{array}$ & FE 2 & $\begin{array}{l}\text { Graphic (2a: Actual enactment; 2b: Verbally } \\
\text { described; 2c: Using available materials) }\end{array}$ \\
\hline TR 3 & $\begin{array}{l}\text { Exemplifying-Illustrative (3a: Exemplifying instance; 3b: } \\
\text { Exemplifying situation; 3c: Exemplifying scene) }\end{array}$ & FE 3 & $\begin{array}{l}\text { Motoric (3a: Actual enactment; 3b: Verbally } \\
\text { described; 3c: Using available materials) }\end{array}$ \\
\hline \multirow[t]{2}{*}{ TR 4} & $\begin{array}{l}\text { Metaphoric-Symbolic (4a: Interpretation; 4b: Conventional } \\
\text { metaphor; 4c: Original metaphor; 4d: Symbol) }\end{array}$ & FE4 & $\begin{array}{l}\text { Sounds and Tones (4a: Actual enactment; 4b: } \\
\text { Verbally described; 4c: Using available materials) }\end{array}$ \\
\hline & & FE5 & $\begin{array}{l}\text { Denotative (5a: Actual enactment; } 5 \mathrm{~b} \text { : Verbally } \\
\text { described; 5c: Using available materials) }\end{array}$ \\
\hline
\end{tabular}

Table 1: Major Variables of the Meaning System: The Meaning Variables (30)

Note. The table does not include the meta-meaning variables.

${ }^{a}$ Modes of meaning: Lexical mode: TR1+TR2; Personal mode: TR3+TR4

${ }^{\mathrm{b}}$ Close SR: $1+3+9+12$ Medium SR: 2+4+5+10+11 Distant SR: 6+7+8+13

'This meaning dimension includes a listing of subcategories of the different senses/sensations: [for special purposes they may also be grouped into "external sensations" and "internal sensations"] e.g., color, form, taste, sound, smell, pain, humidity and various internal sensations. 


\begin{tabular}{|c|c|c|c|}
\hline Type of meaning variables & Definition & Examples of categories & Examples of coded responses \\
\hline Meaning dimensions & $\begin{array}{l}\text { Characterize the contents of } \\
\text { the meaning values from the } \\
\text { viewpoint of the specific com- } \\
\text { municated information }\end{array}$ & $\begin{array}{l}\text { Sensory qualities, Emotions, } \\
\text { Function, Consequences and } \\
\text { results }\end{array}$ & $\begin{array}{c}\text { Street: long } \\
\text { Meaning dimension: Size and } \\
\text { dimensions }\end{array}$ \\
\hline Types of relation & $\begin{array}{l}\text { Characterize the immediacy of } \\
\text { the relation between the refer- } \\
\text { ent and the cognitive contents }\end{array}$ & $\begin{array}{c}\text { Attributive (of a quality or } \\
\text { action), Comparative (similar, } \\
\text { different), illustrative exemplify- } \\
\text { ing, metaphoric }\end{array}$ & $\begin{array}{l}\text { Summer: warmer than spring } \\
\text { Type of relation: comparative }\end{array}$ \\
\hline Forms of relation & $\begin{array}{l}\text { Characterize the formal regula- } \\
\text { tion of the relation between } \\
\text { the referent and the cognitive } \\
\text { contents: its validity, quantifica- } \\
\text { tion and status }\end{array}$ & $\begin{array}{c}\text { Validity: Positive or nega- } \\
\text { tive; Quantification: Absolute, } \\
\text { partial; Status: factual, desired, } \\
\text { desirable }\end{array}$ & $\begin{array}{l}\text { Yoga: It is not a religion Form of } \\
\text { relation: negative Law: should be } \\
\text { obeyed. Form of relation: Desired }\end{array}$ \\
\hline Referent Shifts & $\begin{array}{l}\text { Characterize the relation } \\
\text { between the referent and the } \\
\text { original input or the former } \\
\text { referent }\end{array}$ & $\begin{array}{l}\text { A referent may be identical to } \\
\text { the input or the former referent; } \\
\text { it may be its opposite; a part of } \\
\text { it; unrelated to it }\end{array}$ & $\begin{array}{l}\text { The input was "car" and the re- } \\
\text { sponse was: a Ford rides fast. } \\
\text { Referent shift: the referent is a } \\
\text { part of the input }\end{array}$ \\
\hline Forms of expression & $\begin{array}{l}\text { Characterize the forms of ex- } \\
\text { pression of the meaning units }\end{array}$ & $\begin{array}{l}\text { Verbal, Denotation, Drawing, } \\
\text { Description of a gesture }\end{array}$ & $\begin{array}{l}\text { The input was Street and the } \\
\text { response - drawing of a street. } \\
\text { Form of expression: graphic }\end{array}$ \\
\hline
\end{tabular}

Table 2: The meaning variables: The types, definitions, examples of categories and the categories and examples of coded responses (14)

Note. Meta-meaning, a sixth type of meaning variables, which characterize the attitude of the individual to the meaning communication is not presented in the table because of its marginal significance in the present context

found to correspond to patterns of meaning variables. Accordingly, we expected that a pattern of meaning variables would be found to correspond to an experience such as MP that includes both the component of loss of meaningfulness of life and an emotion.

\section{Hypotheses}

The hypotheses were first, that a pattern of meaning variables would be found to correspond to MP in the present and to MP in the past; second, that the pattern of meaning variables corresponding to MP in the present and to MP in the past would enable predicting the levels of MP in the present and MP in the past.

\section{Participants}

The sample included 61 subjects, 28 women and 33 men. Their mean age was 25.03 years ( $\mathrm{SD}=5.56$ ) ranging from 18 to 41 years. The majority ( $\mathrm{n}=48$ ) were unmarried, 10 married and 3 divorced. Most of the subjects were born in Israel $(n=56)$, the rest in other countries. According to self-reports 48 described themselves as Jewish non-religious, and 13 as Jewish observant. They have been diagnosed and treated $\mathrm{M}=12.84$ ( $\mathrm{SD}=7.15$ ) years earlier, when their mean age at that time was 12.2 (SD $=5.13$ ) years, for pediatric cancer, mostly lymphoma [27] and leukemia [14] or other diagnoses (brain tumors and sarcoma).
Tools

All subjects were administered the following questionnaires

(a) A background information questionnaire designed to provide demographic and medical data about the subjects (e.g., gender, date of birth, cancer diagnosis in the past); (b) The MP questionnaire [23] which provides scores about MP at present, and MP in the past (during diagnosis and treatments). The parts referring to MP at present and in the past were identical except for the instructions which referred either to the present or the past. The MP questionnaire includes 45 items, each with 5 response alternatives ('strongly disagree' to 'strongly agree', scored as 1 to 5 , respectively), referring to the following themes: loss of control; irreversibility of pain; emotional flooding; narcissistic wounds (i.e. sense of being abandoned); estrangement from oneself; confusion; need for social support; emptiness; freezing (i.e., sense of being paralyzed). The overall MP score was taken as the mean across all items. The questionnaire was validated in different samples [26,34]. The reliability scores were Cronbach's $\alpha=.97$ for MP at present and Cronbach's $\alpha$ $=.97$ for MP in the past. (c) The questionnaire of meanings. It was constructed similarly to the Test of Meanings [28] and required the subjects to communicate to someone else of their choice the interpersonal common meaning and the personal subjective meaning, 
using any adequate means of expression, of the following 8 words: cancer, hospital, physician, oncology, chemotherapy, examinations, treatments, leukemia/non-Hodgkins lymphoma/Hodgkins lymphoma/sarcoma/Ewing (selecting as stimulus the specific disease they personally had). The responses were coded in terms of the meaning system: first they were analyzed into meaning units, and then each meaning unit was characterized by one meaning dimension, one type of relation, one form of relation, one shift of referent and one form of expression. The codings across all responses to the 8 word stimuli were summed, for each set of meaning variables separately. The coding was done on a computer system [35] and yielded five sets of scores, one for each of the five sets of meaning variables. Since all responses were verbal the meaning variables of mode of expression were not considered further in the study due to absence of variability. The inter-coder reliability was satisfactory: The correlations between the summative scores for the five sets of meaning variables based on the codings of two independent coders ranged from.89 to. 92 .

\section{Procedure}

During the data collection period which lasted 6 months, all pediatric cancer survivors who met the inclusion criteria were addressed at their routine follow-up visit to the outpatient clinic in a major tertiary medical center in Israel. After presenting the study to the subjects they were asked to sign the consent form and to participate in the study by completing the questionnaires while waiting for their routine check-up at the survivors' hematology-oncology clinic. The questionnaires were presented unanimously in random order. An experimenter was available for help if the patients asked for it. The study protocol was approved by the institutional ethics committee of "Rabin Medical Center" (212RMC).

\section{The statistical analyses}

1. The means and SD's of the variables.

2. Factor analysis of the dimensions of meaning variables. (Extraction Method: Principal Component Analysis. Rotation Method: Oblimin with Kaiser Normalization.

3. Relations between MP present and MP past with the factors of meaning variables.

4. Regression analysis of MP at present and MP past with control variables and factors of meaning variables as predictors

\section{Results}

The means and SD's for MP at present and MP in the past were 1.719 [.529], 2.530 [.862], respectively. MP at present and MP in the past were correlated positively $(r=.588, \mathrm{p}<.001)$. Accordingly, the study focused on identifying the meaning variables corresponding to both MP at present and to MP in the past rather than only to one or the other.

\section{Factor analyses of the sets of meaning variables}

Analysis of the meaning variables proceeded in two phases. First, each of the four sets of meaning variables was factor analyzed separately. Table 3 presents the results of the factor analysis of the meaning dimensions. The results showed four factors accounting together for $34.798 \%$ of the variance. The first and most salient factor represents focusing on the objective dynamic-functional aspects of external reality (Meaning dimensions 8a, 8b, 3, 4a, 4b) while suppressing one's personal approach (Meaning dimensions minus loadings of 20b, 21b, 19b, 6, and 7). The second factor is focused on contextual aspects of external reality (Meaning Dimensions 17b, 15, 19a, 9, 21b) and may be labelled contextual-perceptual aspects of reality. The third factor is focused on cognitions, and external characteristics of objects that are not immediately evident perceptually (Meaning dimensions 22a, 22b, 12,13, 18, 17b minus), and may be labelled as representing cognitive and formal aspects of objects. The fourth factor focuses on structural aspects, categorical and analytical, suppressing time and state of objects (Meaning dimensions 5, 2b, 1, 10, and 11 minus, 16 minus) and may be labelled structural-categorical aspects of objects and situations.

Table 4 presents the results of the factor analysis of the second set of meaning variables which deals with types of relation. There were four factors, accounting together for $54.056 \%$ of the variance. In this set the first factor represents the comparative types of relation (TR2c, TR2b), emphasized by excluding the attributive type of relation (1a minus). Hence, it may be labelled comparison. The second factor represents the interpersonal types of relation emphasizing the more unique contributions of examples (TR3a) and personal interpretations (TR4a) but excluding the metaphor (4d minus). Hence, it represents interpersonal meaning (with example and interpretation) and may be labelled interpersonal meaning. The third factor is defined by the following meaning variables: TR4c, TR4b, and TR2d. It represents two kinds of metaphoric relations (both the standard TR4b and the personal TR4c) and the interactional relations (TR2d). Hence it may be labelled metaphoric meaning. The fourth factor is defined by the following variables: TR2a, TR3b, and TR3c. It represents analogies of similarity (TR2b), and exemplifying-illustrative relations by means of images of situations (TR3b) and dynamic scenes (TR3c). Hence, it may be labelled label: concrete demonstration/illustration). Hence it may be labelled concrete demonstrations. 


\begin{tabular}{|c|c|c|c|c|}
\hline Meaning variables & Factor I & Factor II & Factor III & Factor IV \\
\hline $\operatorname{dim} 21 a$ & -.774 & & & \\
\hline $\operatorname{dim} 20 a$ & -.689 & & & \\
\hline $\operatorname{dim} 8 \mathrm{a}$ & .635 & & & \\
\hline $\operatorname{dim} 4 a$ & .556 & & & \\
\hline $\operatorname{dim} 14$ & -.493 & & & \\
\hline $\operatorname{dim} 20 b$ & -.486 & & & \\
\hline $\operatorname{dim} 8 b$ & .477 & & & \\
\hline $\operatorname{dim} 3$ & .447 & & & \\
\hline $\operatorname{dim} 7$ & -.424 & & & \\
\hline $\operatorname{dim} 2 a$ & .415 & & & \\
\hline $\operatorname{dim} 19 b$ & -.367 & & & \\
\hline $\operatorname{dim} 4 b$ & .366 & & & \\
\hline $\operatorname{dim} 6$ & -.200 & & & \\
\hline $\operatorname{dim} 9$ & & .701 & & \\
\hline $\operatorname{dim} 17 a$ & & .695 & & \\
\hline $\operatorname{dim} 15$ & & .682 & & \\
\hline $\operatorname{dim} 19 a$ & & .641 & & \\
\hline $\operatorname{dim} 21 b$ & & .162 & & \\
\hline $\operatorname{dim} 17 b$ & & -.133 & & \\
\hline $\operatorname{dim} 22 a$ & & & .704 & \\
\hline $\operatorname{dim} 18$ & & & .676 & \\
\hline $\operatorname{dim} 13$ & & & .621 & \\
\hline $\operatorname{dim} 12$ & & & .613 & \\
\hline $\operatorname{dim} 22 b$ & & & -.142 & \\
\hline $\operatorname{dim} 5$ & & & & .717 \\
\hline $\operatorname{dim} 2 b$ & & & & .613 \\
\hline $\operatorname{dim} 1$ & & & & .420 \\
\hline $\operatorname{dim} 16$ & & & & -.406 \\
\hline $\operatorname{dim} 10$ & & & & .383 \\
\hline $\operatorname{dim} 11$ & & & & -.212 \\
\hline Eigenvalue & 3.897 & 2.350 & 2.180 & 2.012 \\
\hline Per cent of variance & 12.991 & 7.832 & 7.268 & 6.707 \\
\hline Suggested label & $\begin{array}{l}\text { Objective dynamic- } \\
\text { functional aspects }\end{array}$ & $\begin{array}{c}\text { Contextual-perceptual } \\
\text { aspects }\end{array}$ & $\begin{array}{c}\text { Cognitive and formal } \\
\text { aspects }\end{array}$ & $\begin{array}{c}\text { Structural-categorical } \\
\text { aspects }\end{array}$ \\
\hline
\end{tabular}

Table 3: Results of factor analysis of the dimensions of meaning variables.

Note. Extraction Method: Principal Component Analysis. Rotation Method: Oblimin with Kaiser Normalization. The presented factor loadings are those that in each column are higher than those in the adjoining one. For the definition of the variables in the first column, please see Table 1. 


\begin{tabular}{|c|c|c|c|c|}
\hline Meaning variables & Factor 1 & Factor 2 & Factor 3 & Factor 4 \\
\hline TR2c & .872 & & & \\
\hline TR2b & .804 & & & \\
\hline TR1a & -.731 & & & \\
\hline TR1b & & -.889 & & \\
\hline TR3a & & .756 & & \\
\hline TR4a & & .521 & & \\
\hline TR4d & & -.263 & & \\
\hline TR4c & & & .739 & \\
\hline TR4b & & & .677 & \\
\hline TR2d & & & .636 & \\
\hline TR2a & & & & .748 \\
\hline TR3b & & & & 633 \\
\hline TR3c & & & & .392 \\
\hline Eigenvalue & 2.302 & 1.910 & 1.539 & 1.277 \\
\hline Per Cent of variance & 17.710 & 14.691 & 11.836 & 9.820 \\
\hline Suggested label & Comparison & Interpersonal meaning & Metaphoric meaning & Concrete demonstrations \\
\hline
\end{tabular}

Table 4: Results of the factor analysis of the types of relation meaning variables.

Note. Extraction Method: Principal Component Analysis. Rotation Method: Oblimin with Kaiser Normalization.

The presented factor loadings are those that in each column are higher than those in the adjoining one.

Table 5 presents the results of the factor analysis of the third set of meaning variables that deal with forms of relation. The analysis yielded three factors which accounted together for $54.428 \%$ of the variance. The first factor is defined by the meaning variables FR1b, FR1a minus, FR 5b, FR4b. It clearly represents the negative forms of relation in regard to propositional (FR1b), conjunctive (FR 4b) and disjunctive (FR5b) statements, excluding the positive declarative relation (FR1a). It may be labelled the negative relations. The second factor is defined by the meaning variables FR4a, FR6a, FR3a which represent the positive relations in regard to the conjunctive (FR4a), universal (FR3a) and normative (FR6a) statements. Hence, it may be labelled the positive relations. The third factor is defined by FR2a, FR2b and FR5a, which represent the partial (FR2a, FR2b) and disjunctive relations. Hence it may be labelled restrictive-disjunctive relations.

Table 6 presents the results of the factor analysis of the fourth set of meaning variables that deal with shifts of referent. The analysis yielded four factors which accounted together for $57.999 \%$ of the variance. The first factor is defined by the variables associations (SR6minus), elaborating previous referent (SR5), modifying previous referent (SR4) or combining several previous referents
(SR10). It may be labelled elaborating former referents. The second factor is defined by denying the presented referent (SR1 minus) and focusing on parts of it (SR3). It may be labelled as focus on parts of the original referent. The third factor is defined by the variables denying the verbal label (SR8 minus) and focusing on the opposite (SR2) or unrelated referents (SR7). It may be labelled as shifting to an opposite or unrelated referent. Factor 4 is defined by the variables SR9 (grammatical variation of the original referent) with a very low loading on SR11 (shifting to a superordinate referent). Hence, it may be labelled focus on grammatical features as the referent.

Relations between MP present and MP past with the factors of meaning variables

For the purpose of analyzing the relations between MP in the present and MP in the past with the sets of meaning variables, the MP at present and MP in the past were correlated with the factors representing the four sets of meaning variables. Only those factors of the meaning variables that were found to be correlated significantly with both MP present and MP past were selected as components for the meaning profile corresponding to MP. 


\begin{tabular}{|l|c|c|c|}
\hline \multicolumn{1}{|c|}{ Meaning variables } & Factor I & Factor II & Factor III \\
\hline FR1b & .954 & & \\
\hline FR1a & -.944 & & \\
\hline FR5b & .482 & & \\
\hline FR4b & .352 & .811 & \\
\hline FR6a & & .757 & \\
\hline FR4a & & .467 & .851 \\
\hline FR3a & & & .756 \\
\hline FR2a & & & -.185 \\
\hline FR2b & & & 1.524 \\
\hline FR5a & & & \\
\hline Eigenvalue & 2.334 & 1.586 & 15.235 \\
\hline Per Cent of variance & 23.336 & Positive relations & Restrictive-Disjunctive relations \\
\hline Suggested label & Negative relations & & \\
\hline
\end{tabular}

Table 5: The results of the factor analysis of the forms of relation meaning variables.

Extraction Method: Principal Component Analysis. Rotation Method: Oblimin with Kaiser Normalization.

The presented factor loadings are those that in each column are higher than those in the adjoining one.

\begin{tabular}{|c|c|c|c|c|}
\hline Meaning variables & Factor I & Factor II & Factor III & Factor IV \\
\hline SR6:Association & -.948 & & & \\
\hline SR5: Previous meaning value & .805 & & & \\
\hline $\begin{array}{l}\text { SR4: Former referent modified } \\
\text { by addition }\end{array}$ & .617 & & & \\
\hline $\begin{array}{l}\text { SR10: Former meaning values } \\
\text { combined }\end{array}$ & .527 & & & \\
\hline $\begin{array}{l}\text { SR1: Identical to presented ref- } \\
\text { erent }\end{array}$ & & -.935 & & \\
\hline SR3: Part of presented referent & & .813 & & \\
\hline SR8: Verbal label & & & -.656 & \\
\hline SR2: Opposite & & & .601 & \\
\hline SR7: Unrelated & & & .596 & \\
\hline SR9: Grammatical variation & & & & .853 \\
\hline SR11: Superordinate referent & & & & .191 \\
\hline Eigenvalue & 2.267 & 1.745 & 1.234 & 1.523 \\
\hline Per cent of variance & 20.608 & 15.864 & 11.215 & 19.213 \\
\hline Suggested label & $\begin{array}{l}\text { Elaborating former } \\
\text { referents }\end{array}$ & $\begin{array}{l}\text { Focus on parts of the } \\
\text { original referent }\end{array}$ & $\begin{array}{l}\text { Shifting to an opposite } \\
\text { or unrelated referent }\end{array}$ & $\begin{array}{l}\text { Focus on grammatical } \\
\text { features }\end{array}$ \\
\hline
\end{tabular}

Table 6: Results of factor analysis of the referent shift meaning variables

Note. Extraction Method: Principal Component Analysis. Rotation Method: Oblimin with Kaiser Normalization. The presented factor loadings are those that in each column are higher than those in the adjoining one. For the definition of the variables in the first column please see Table 1. 
The original list of factors representing the meaning variables (see Tables 3-6) included 15 factors. But only eight factors were correlated with both MP at present and MP in the past. The list included the following factors: Third factor of the meaning dimensional factors (DIMI): cognitions and formal characteristics of objects; fourth factor of the type of relations factors (TRIV): concrete demonstrations; first factor of the forms of relations factors (FRI): negative forms of relation; second factor of the forms of relations factor (FRII): positive forms of relation; first factor of the referent shift factors (SRI): elaborating previous referents; second factor of the referent shift factors (SRII): focusing on partial referents; third factor of the referent shift factors (SRIII): focusing on opposite or unrelated referents; fourth factor of the referent shift factors (SRIV): focus on grammatical features as referent. These eight factors will be used in the next analyses as meaning-based predictor variables. There were intercorrelations between them only in two cases (the first and the second referent shift factors were correlated with the first factor of forms of relation, $r=.292, p<.05$ ).

In order to examine the hypothesis that the set of the meaning factors would enable predicting the level of MP in the present and in the past regression analyses were performed with the eight meaning-based predictor variables and the MP at present and the MP in the past as dependent variables. The regression analyses were in two steps. In the first step the control factors of age, gender and marital status were introduced. In the second step all the eight meaning-based predictor variables were entered in the analyses. Table 7 presents the results of the regression analysis in regard to MP at present. It shows that the whole model yielded significant results both for the control variables as well as when the meaning-based predictor variables were added. For the whole model, the amount of variance accounted for is $34.1 \%$. There are only two coefficients with significant contributions. It is gender (i.e., being female) and the first factor of forms of relation (FRI) which represents the tendency for negation.

Table 8 presents the results of the regression analysis for MP in the past. It shows that the control variables alone did not yield a significant result but adding the meaning-based predictor variables yielded an addition to the prediction that was significant and turned the whole model into significant. The amount of variance accounted for was $38.5 \%$. There were three meaning-based predictor variables with significant contributions: the third meaning dimensional factor (DIMIII) which represents cognitive and formal characteristics of objects; the first referent shift factor (SRI) which represents focusing on the elaboration of previous responses; and the fourth referent shift factor (SRIV) which represents focusing

\begin{tabular}{|l|c|c|c|}
\hline \multirow{2}{*}{ Predictors } & $\begin{array}{c}\text { Unstandardized } \\
\text { coefficients }\end{array}$ & $\begin{array}{c}\text { Standardized } \\
\text { coefficients }\end{array}$ & \multirow{2}{*}{ t-test } \\
\cline { 2 - 3 } & B Std error & Beta & \\
\hline Constant & 1.682 .371 & & $4.530^{* * *}$ \\
\hline Gender & .342 .131 & .324 & $2.613^{*}$ \\
\hline Marital status & .300 .202 & .234 & 1.486 \\
\hline Age at present & -.007 .015 & -.077 & -.488 \\
\hline Constant & 1.610 .378 & & $4.258^{* * *}$ \\
\hline Gender & .210 .136 & .200 & 1.553 \\
\hline Marital status & .352 .211 & .275 & 1.670 \\
\hline Age at present & -.002 .016 & -.025 & -.153 \\
\hline Factor DIMIII & .063 .063 & .122 & .993 \\
\hline Factor SRIV & .109 .088 & .162 & 1.240 \\
\hline Factor FRI & .250 .081 & .474 & $3.086^{* *}$ \\
\hline Factor TRIV & .089 .073 & .148 & 1.220 \\
\hline Factor SRII & -.094 .067 & -.182 & -1.401 \\
\hline Factor SRI & .088 .073 & .167 & 1.206 \\
\hline Factor SRIII & -.045 .063 & -.086 & -.708 \\
\hline FRII & .052 .062 & .101 & .840 \\
\hline
\end{tabular}

Table 7: Two-step regression analysis of MP at present with control variables and factors of meaning variables as predictors.

Step $1: \mathrm{R}^{2}=.161 \mathrm{~F}$ change $=3.634, \mathrm{df}=5 / 57, \mathrm{p}<.05$ overall $\mathrm{F}=3.634$, $\mathrm{df}=3 / 60, \mathrm{p}<05$.

Step 2: $\mathrm{R}^{2}=.341 \mathrm{~F}$ change $=2.683, \mathrm{df}=8 / 49, \mathrm{p}<.05$ overall $\mathrm{F}=2.310$, $\mathrm{df}=11 / 60, \mathrm{p}<.05$.

For interpreting the meaning variable factors in column 1, please see tables 3-6.

on grammatical features of the referent. The last mentioned variable is the meaning-based predictor with the highest loading and highest level of significance.

\section{Discussion}

The study deals with the correlates of MP at present and MP in the past in terms of sets of meaning variables. The findings confirm the general expectation that MP in the present and MP in the past are related to meaning variables. The findings show that there is a set of meaning-based factors related to MP in the present and to MP in the past which can be considered as the meaning profile of MP. This conclusion provides support for the first hypothesis.

The meaning profile of MP can be analyzed in terms of its formal characteristics and in terms of its contents. In terms of formal characteristics this meaning profile turns out to be comparable to the profiles of personality traits only in the number of components 
but not in terms of the other criteria (i.e., the proportion of meaning variables from the four sets of factors, and the number of negative correlations).

The meaning profile of MP is characterized by the salience of factors representing shifts of referent. It includes all four factors representing shift of referent (SR) meaning variables. The factors of the SR meaning variables describe the variety of processes enabling shifting away from a presented referent or focusing on it. Notably, the shift of referent factors in the present study are characterized by limiting oneself to elaborating the same components of the presented referent (Factor SRI), or focusing on parts of the original referent (Factor SRII), shifting to opposite or unrelated referents (Factor SRIII), or focusing on the grammatical features of the original referent (Factor SRIV. Factors SRI, SRII and SRIV represent processes manifesting different maneuvers of focusing specifically on the presented referent. Factor SRIII represents some kind of shifting away from the presented referent but to the opposite (which is not too far) or to unrelated referents (which express evasion). Factor SRIV is characterized by focusing on the grammatical features of the referent, which clearly suggests overlooking completely the referent's meaning. That which is clearly missing in these SR processes is evidence for an effort to elaborating the original referent, expanding its meaning, exploring its associations in order to comprehend its underlying meaning and thus overcome its emotional control over oneself.

In addition to the described SR meaning factors the meaning profile of MP includes two FR factors: one representing the negative relation (FRI) and one representing the positive relations (FR2). Both factors are of interest in the present context. The positive relations have a declarative definitive sense about them. But the negative relations express a negation, a denial, the absence or non-being of something [46]. Studies showed that the use of negation expresses an effort to avoid a theme, to approach it at best indirectly, to overlook its unique characteristics [47]. It is also related to a certain degree of difficulty in comprehending, in increased number of errors and delayed reaction time [48]. Notably, negation also plays a role in emotional regulation, increasing the attempt to reevaluate a theme while inhibiting the response evoked by that theme [49]. In sum, the factor of negation (FR1) implies a tendency to cover up cognitively some theme, avoid it emotionally, and inhibit a behavioral reaction to it.

The two additional meaning factors fit in well with the above described meaning factors, enhancing the tendencies expressed by the other factors in the meaning profile. Thus, the dimensional factor (DIMIII) adds the emphasis on cognitive and formal characteristics of objects and the Factor TRIV adds the tendency for concrete demonstrations. Both factors enhance the above described tendencies of avoiding dealing with the core meanings of a presented theme. In the present context this theme is most likely to be the suffering and pain caused by the cancer disease and the treatments in one's childhood.

The findings provide support also for the second hypothesis which was that the meaning profile of MP would enable predicting the level of the scores of MP in the present and MP in the past. The two regression analyses show that as expected the predictions are significant in regard to both MP at present and MP in the past. There are however two findings relating to these regressions that were unexpected. One finding related to the meaning-based factors that played a prominent role in each of these predictions and the second findings was the difference in the number of meaning-based factors that had significant contributions to predicting MP at present and MP in the past (1 vs 3 ).

In regard to MP at present it was the factor FR1 that represents the tendency for negation. In regard to MP in the past there were three meaning-based factors with significant contributions: dimensional factor III: cognitive and formal characteristics, Factor SRIV representing shifting to the actually irrelevant grammatical features of the input, and SRI which represents focusing on former responses. The difference between the factors playing a prominent role in regard to MP in the present and MP in the past suggests a possible difference in handling these two aspects of MP. While MP in the present is a kind of open experience which may be accessed personally and related to present experiences, MP in the past is a kind of closed experience that tends to be dissociated from the present. Hence its score is higher and its meaning potentially broader; it does not have to be closed up and blocked by negation tendencies to the same extent as MP at present.

The findings have theoretical and practical implications. The major theoretical implication is that the study is the first example of exploring the meaning correlates of a construct by using a Meaning Test with stimuli that differ completely from those in the standard Test of Meanings in number (8 vs 11), and content (referring to the context of the study vs neutral/standard). Nevertheless the findings are encouraging and support the methodological innovation of applying contextually relevant tests of meaning.

The practical implications of the study refer to the guidelines it provides for helping survivors in coping with the MP experiences. The findings indicate which meaning variables need to constitute 
the targets for an intervention. If the goal is to reduce MP then the memories and past experiences need to be elaborated more widely, in terms of a rich variety of meaning variables including temporal and locational aspects, and other new features that would allow the evocation of new emotional responses. These could provide the context for integrating the past experiences into one's overall functioning at present. This kind of broad meaning-based systematic elaboration of the past experiences may help the survivors overcome the pain and reabsorb the past experiences into their present life and functioning in a productive manner. In this way, the past experiences may lose their painful restrictive connotations and turn instead into a positive contribution to one's quality of life.

The limitations of the study refer mainly to the small size of the sample and the reliance only on single measures of MP and of the cognitive correlates. In view of the encouraging results of the present study, it would be necessary and advisable to repeat the study in a larger sample in which more measures of MP and cognitive correlates would be applied as well as exploration of the relations of MP with the current state of the survivors and their diagnoses and treatments in the past.

\section{Bibliography}

1. Kreitler S. "The meaning profiles of anxiety and depression: Similarities and differences in two age groups". Cognition and Emotion 32.7 (2017a):1499-1513.

2. Kreitler S. "Personality traits as patterns of meaning assignment tendencies". Journal of Personality 86.1 (2018): 55-68.

3. Kreitler $\mathrm{S}$ and Kreitler H. "The cognitive foundations of personality traits". New York: Plenum (1990a).

4. Kreitler $\mathrm{H}$ and Kreitler S. "The psychosemantic foundations of creativity". In K. J. Gilhooly, M. Keane, R. Logie and G. Erdos (Eds.), Lines of thought: Reflections on the psychology of thinking 2 (1990b): 191-201.

5. Kreitler $\mathrm{H}$ and Kreitler S. "The psychosemantics of responses to questions". In K. J. Gilhooly, M. Keane, R. Logie and G. Erdos (Eds.) Lines of thought:Reflections on the psychology of thinking 1 (1999c): 15-28.

6. Kaatsch P. "Epidemiology of childhood cancer". Cancer Treatment Reviews 36.4 (2010): 277-285.

7. Hudson MM., et al. "Health status of adult long-term survivors of childhood cancer: A report from the Childhood Cancer Survivor Study". Journal of the American Medical Association 290.12 (2003): 1583-1592.
8. Baumeister RF. "Suicide as escape from self". Psychological Review 97.1 (1990): 90-113.

9. Kurtz BP., et al. "Pediatric consultation". In T. A. Stern, G. L. Fricchione, N. H. Cassem, M.S. Jellinek, and J. Rosenbaum (Eds.) Handbook of general hospital psychiatry (2010): 565582.

10. Reinfjell T., et al. "A Review of Demographic, Medical, and Treatment Variables Associated with Health-Related Quality of Life (HRQOL) in Survivors of Hematopoietic Stem Cell (HSCT) and Bone Marrow Transplantation (BMT) during Childhood". Frontiers in Psychology 8 (2017): 253.

11. Tremolada M., et al. "Self-esteem and academic difficulties in preadolescents and adolescents healed from paediatric leukaemia". Cancers 9.6 (2017): 55

12. Rhee MA., et al. "Impact of psychological and cancer-related factors on HRQoL for Korean childhood cancer survivors". Quality of Life Research 23.9 (2014): 2603-2612.

13. Zeller B., et al. "Chronic fatigue in long-term survivors of childhood lymphomas and leukemia: Persistence and associated clinical factors". Journal of Pediatric Hematology Oncology 36.6 (2014): 438-444.

14. Calaminus G., et al. "Support Care Cancer" 22 (2014): 1519 $-1529$.

15. Ganz FD., et al. "Post-traumatic stress disorder in Israeli survivors of childhood cancer". Oncology Nursing Forum 37.2 (2010): 160-167.

16. Teta MJ., et al. "Psychosocial consequences of childhood and adolescent cancer survival". Journal of chronic diseases 39.9 (1986): 751-759.]

17. Wengenroth L., et al. "Life partnerships in childhood cancer survivors, their siblings, and the general population". Pediatric blood and cancer 61.3 (2014): 538-545.

18. Twombly R. "Decades after cancer, suicide risk remains high", Journal of the National Cancer Institute 98.19 (2006): 13561358.

19. Recklitis CJ., et al. "Suicide ideation in adult survivors of childhood cancer: a report from the Childhood Cancer Survivor Study". Journal of Clinical Oncology 28.4 (2010): 655-661.

20. Recklitis CJ., et al. "Suicidal ideation and attempts in adult survivors of childhood cancer". Journal of Clinical Oncology 24.24 (2006): 3852-3857. 
21. Brinkman-Stoppelengurg A., et al. "The effects of advance care planning on end-of-life care: A systematic review". Palliative Medicine 28.8 (2014): 1000-1025.

22. Raz H., et al. "Mental pain in Israeli adult childhood cancer survivors and its effects on their quality of life". Journal of Psychology and Psychotherapy 6 (2016): 258.

23. Orbach I., et al. "Mental pain: a multidimensional operationalization and definition". Suicide and Life-Threatening Behavior 33.3 (2003): 219-230.

24. Meerwijk EL and Weiss SJ. "Toward a unifying definition of psychological pain". Journal of Loss and Trauma 16.5 (2011): 402-412.

25. Levi Y., et al. "Mental pain and its communication in medically serious suicide attempts: an "impossible situation". Journal of Affective isorders 111.2 (2008): 244-250.

26. Soumani A., et al. "Mental pain and suicide risk: application of the Greek version of the Mental Pain and the Tolerance of Mental Pain scale". Psychiatriki 22.4 (2011): 330-340.

27. Bakan D. "Disease, pain, and sacrifice toward a psychology of suffering". Chicago: University of Chicago Press (1968).

28. Breitbart W., et al. "Psychotherapeutic interventions at the end of life: a focus on meaning and spirituality". The Canadian Journal of Psychiatry 49.6 (2004): 366-372.]

29. Van As AB., et al. "Gunshots to the neck: selective angiography as part of conservative management". Injury 33.5 (2002): 453-456.

30. Kreitler S. "Meaning correlates of value orientations". In F. Deutsch, M. Boehnke, U. Kühnen, and K. Boehnke (Eds.), Rendering borders obsolete. Bernen: International Association for Cross-Cultural Psychology (2011): 52-70.

31. Casakin H and Kreitler S. "The cognitive profile of creativity in design". Thinking Skills and Creativity 6.3 (2011): 159-168.

32. Kreitler S. "The psychosemantic approach to logic". In S. Kreitler, L. Ropolyi, D. Eigner and G. Fleck (Eds.) States of consciousness, systems of logic and the construction of order Bern, New York, Vienna: Peter Lang Publishing Group (2012): 33-62.

33. Kreitler $\mathrm{H}$ and Kreitler S. "Artistic value judgments and the value of judging the arts". Leonardo 16 (1983): 208-211.

34. Guimarães R., et al. "Validation of the Orbach and Mikulincer Mental Pain Scale (OMMP) on a drug addicted population". Social Psychiatry and Psychiatric Epidemiology 49.3 (2014): 405-415.
35. Kreitler S. (2010).

36. Kreitler S and Kreitler H. "Types of curiosity behaviors and their cognitive determinants". Archives of Psychology 138.4 (1986a) 233-251.

37. Kreitler S and Kreitler H. "Individuality in planning: Meaning patterns of planning styles". International Journal of Psychology 21 (1986b): 565-587.

38. Kreitler S and Kreitler H. "The psychosomatic structure of narrative". Semiotica 58 (1986c): 217-243.

39. Kreitler S and Kreitler H. "The motivational and cognitive determinants of individual planning". Genetic, Social and General Psychology Monographs 113 (1987a): 81-107.

40. Kreitler S and Kreitler H. "Plans and planning: Their motivational and Cognitive antecedents". In S. L. Friedman, E. K. Scholnick and R. R. Cocking (Eds.), Blueprints for thinking: The role of planning in cognitive development New York: Cambridge University Press (1987b): 110-178.

41. Kreitler S and Kreitler H. "Horizontal decalage: A problem and its resolution". Cognitive Development 4 (1989): 89-119.

42. Kreitler S and Kreitler H. "Motivational and cognitive determinants of exploration". In H. Keller, K. Schneider, and B. Henderson (Eds.), Curiosity and exploration New York: SpringerVerlag (1994): 259-284.

43. Kreitler S and Nussbaum S. "Cognitive orientation and interest: The motivational understructure for achievement in mathematics". In L. Hoffmann, A. Krapp, K. Ann Renninger, and J. Baumert (Eds.), Interest and Learning:Proceedings of the Seeon Conference on Interest and Gender Kiel, Germany: Institut fuer die Pedagogik der Naturwissenschaften an der Universitaet Kiel (IPN) (1998): 377-386.

44. Kreitler S., et al. "Cognitive and motivational determinants of academic achievements and behavior in third and fourth grade disadvantaged children". British Journal of Educational Psychology 65.3 (1995): 297-316.

45. Weissler K. "Cognitive determinants of learning to read". Unpublished Master's thesis, School of Psychological Sciences, Tel-Aviv University (1993).

46. Giora R. "When negatives are easier to understand than affirmatives The case of negative sarcasm". In: Larrivée P. and Lee C., editor. Negation and negative polarity: Experimental perspectives, Cham: Springer (2016): 127-143.

47. Ferguson HJ., et al. "Eye-movements and ERPs reveal the time course of processing negation and remitting counterfactual worlds". Brain Research 1236 (2008): 113-125. 
48. Dale R and Duran ND. "The cognitive dynamics of negated sentence verification". Cognitive Science 35.5 (2011): 983996.

49. Herbert C., et al. "No fear, no panic: probing negation as a means for emotion regulation". Social cognitive and affective neuroscience 8.6 (2013): 654-661.

\section{Volume 2 Issue 8 August 2019}

(c) All rights arereserved by Haya Raz and Shulamith

Kreitler. 